\title{
Numerical Study on Optimization of Bulb Type Twisted Rudder for KCS
}

\author{
Myoung-Gil Kim*, Moon-Chan Kim ${ }^{*}$, Yong-Jin Shin ${ }^{*}$ and Jin-Gu Kang* \\ "Department of Naval Architecture \& Ocean Engineering, Pusan National University, Busan, Korea \\ KCS용 벌브형 비대칭 타의 최적화에 대한 수치적 성능 연구 \\ 김명길* 김문찬 $\oplus^{*} \cdot$ 신용진 ${ }^{*}$ 강진구 ${ }^{*}$ \\ *부산대학교 조선해양공학과
}

KEY WORDS: Energy saving device 에너지 저감 장치, Rudder bulb 러더 벌브, Cap 프로펠러 캡, Twisted rudder 비대칭 타, Computational fluid dynamic 전산유체역학

\begin{abstract}
Recently, in an effort to reduce the energy efficiency design index (EEDI), studies on energy saving devices (ESDs) have been conducted. In this study, we designed a post-device suitable for a KRISO container ship (KCS) using computational fluid dynamics (CFD). In order to increase the efficiency of the post-device, a twisted rudder was used, which has a proven performance (showing a 1.34\% reduction in DHP compared to the bare hull at 24 knots) in previous research at Pusan National University. In addition, an increase in efficiency was expected by the use of a rudder bulb, including the discontinuous section of the twisted rudder and a divergent propeller cap to prevent the contraction of the wake. The optimization criterion was the case where the delivery power was the least compared with the bare hull. We analyzed the cause of the efficiency increase through an analysis of the self-propulsion factor. The case study for optimization was divided into 4 types (1. clearance of the bulb and cap, 2. shape of the bulb, 3. size of the bulb and cap, and 4. asymmetric bulb). Finally, with a clearance of $50 \mathrm{~mm}$ from the ship, a spherical bulb with the cap having an angle of $5^{\circ}$, and an asymmetric rudder bulb with a bulb diameter of 1.2HH/1.4H (horizontal/vertical) showed a 2.05\% reduction in DHP compared to the bare hull at 24 knots. We will fabricate a post-device that will be optimized in the future and verify the performance of the post-device through model tests.
\end{abstract}

\section{1. 서 론}

전 세계적으로 환경오염에 대한 관심이 높아짐에 따라 국제 해사기구인 IMO(International Maritime Organization)에서는 EEDI (Energy efficiency design index)라는 지표를 제시하여 선박이 내 는 이산화탄소 배출을 규제하고 있다. 이에 따라 $\mathrm{ESD}(\mathrm{Energy}$ saving device, 에너지 저감 장치)에 대한 연구가 활발히 진행되 고 있다. Carlton(1994)은 다양한 $\mathrm{ESD}$ 를 프로펠러 전방(Zone I ), 프로펠러(Zone II), 프로펠러 후방(Zone III)에 부착되는 ESD로 나 누었다(Fig. 1). 그리고 본 연구에서는 이를 각각 Pre-device, Main-device, Post-device라고 명하겠다.

대표적인 Pre-device로는 Pre-swirl stator(PSS), Pre-swirl duct (PSD) 등이 있으며, Main-device로는 Tip Rake propeller(TRP), Contra-rotating propeller(CRP), 그리고 Post-device로는 비대칭 타 (Twisted rudder), 러더 벌브(Rudderbulb) 등이 알려져 있다.

본 연구는 $\mathrm{ESD}$ 중 Post-device에 대한 연구로 러더 벌브
(Rudder bulb, 벌브) 및 프로펠러 캡(Cap, 캡)을 복합적으로 설계 하여 CFD(Computational fluid dynamics)를 통한 선박의 전달동 력 감소를 확인하였다.

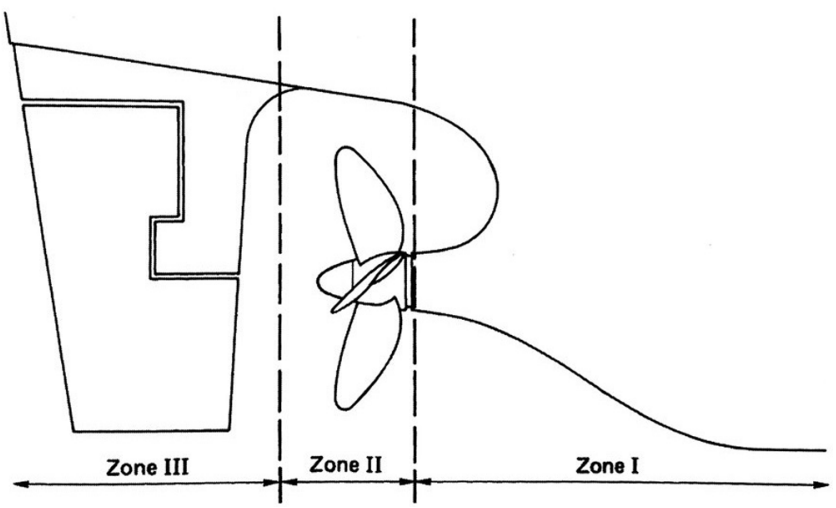

Fig. 1 Zones for classification of energy-saving devices (Carlton, 1994)

Received 31 May 2018, revised 6 November 2018, accepted 13 December 2018

Corresponding author Moon-Chan Kim: +82-51-510-2401, kmcprop@pusan.ac.kr ORCID: http://orcid.org/0000-0002-0452-6830

(C) 2018, The Korean Society of Ocean Engineers

This is an open access article distributed under the terms of the creative commons attribution non-commercial license (http://creativecommons.org/licenses/by-nc/3.0) which permits unrestricted non-commercial use, distribution, and reproduction in any medium, provided the original work is properly cited. 
러더 벌브는 선박의 에너지 효율을 상승시키기 위해 널리 사 용되고 있는 $\mathrm{ESD}$ 로, 일반적으로 알려진 러더 벌브의 유체동역 학적 효과는 다음과 같다(Okada et al., 2015).

(1) Hub vortex 감소

(2) 프로펠러로 인한 후류의 수축 감소

(3) 반류 이득으로 인한 선각효율 향상

초기 러더 벌브는 Costa bulb와 같은 구형 벌브로 설계되어 일반적인 구형 프로펠러 캡과 함께 사용되었다(Mewis and Deichmann, 2013). 그러나 위와 같은 벌브 효과를 더욱 향상시 키기 위해 러더 벌브뿐만 아니라 타(Rudder) 및 프로펠러 캡이 복합적으로 개선되었고, 그에 따라 다양한 Post-device가 개발되 었다.

Nielsen et al.(2012)는 선체를 제외한 Conventional rudder에 Kappel propeller 및 러더 벌브를 사용하여 설계 속도 18.5노트 $(34.262 \mathrm{~km} / \mathrm{h})$ 에서 약 $9.3 \%$ 의 Specified MCR(Maximun continuous rating) 감소 효과를 CFD를 통해 확인하였다. Kim et al.(2014)는 $13,000 \mathrm{TEU}$ 컨테이너선용 비대칭 타에 벌브와 Thrust fin을 적용 하여 약 $2 \%$ 효율 증가를 실험으로 확인 하였다. $\mathrm{Cha}$ (2017)에서 는 KCS(KRISO container ship)선박에 러더 벌브의 크기에 따른 효율을 비교하였다. 그 결과 벌브의 직경이 프로펠러 허브 직경 의 $0.9 \%$ 일 때 약 $1.6 \%$ 효율 증가를 $\mathrm{CFD}$ 를 통해 확인하였다.

그러나 보다 효율적인 $\mathrm{ESD}$ 개발을 위하여 캡과 벌브 사이 간 극, 벌브 형상, 크기 등 Post-device를 세부적으로 나누어 다각적 인 상호 영향 분석이 필요하다. 이에 따라 본 연구에서는 대상 선인 3,600TEU KCS을 기준으로 Post-device를 2가지(러더 벌 브, 캡)로 나누어 설계하였다. Post-device의 효율 증대를 위해 타는 선행연구인 Tae(2017)에서 실험 및 $\mathrm{CFD}$ 를 통해 전달동력 감소 효과가 입증된 비대칭 타를 사용하였으며, 추가적으로 비 대칭 타의 불연속 단면을 포함하는 러더 벌브 및 후류의 수축 을 억제하는 발산형 프로펠러 캡을 사용하여 효율 상승을 기대 하였다. Post-device의 효율 비교는 Bare hull 대비 전달동력이 가 장 적은 case를 목적함수로 두었으며, 자항요소 분석을 통한 효 율 상승 원인을 분석하였다. 추후 최적 설계된 Post-device를 제 작하여 모형시험을 통한 자항 성능을 검증할 예정이다.

\section{Post-device 설계}

\section{1 비대칭 타}

본 연구에 사용된 타는 선행연구인 $\mathrm{Tae}(2017)$ 에서 설계된 Prototype 비대칭 타이다. Tae(2017)에서는 CFD해석을 통해 비 대칭 타에 유입되는 입사각을 파악한 후 설계하고자 하였으나, 비틀림 각이 $30^{\circ}$ 이상 과도하게 결정되어 차선책으로 가장 일반 적으로 사용하는 Prototype $5^{\circ}$ 의 비대칭 타를 사용하였다. Kim et al.(2009)은 유전자 알고리즘을 기법을 사용하여 $12,000 \mathrm{TEU}$ 컨테이너선을 대상으로 캐비테이션이 가장 적은 비대칭 타를 설계하였다. 연구 결과 비틀림 각 7 8도에서 가장 적은 캐비테 이션이 발생되나 이 경우 효율 및 저항관점에서 불리하여 일반 적인 비틀림 각인 $5^{\circ}$ 를 사용하였다. $\mathrm{Heo}(2017)$ 은 $3,600 \mathrm{TEU} \mathrm{KCS}$ 선박에 혼타(Semi-spade rudder)대비 우수한 전달동력 감소 및 양항비를 가지는 비대칭 타를 설계하였다. 비대칭 타의 설계 시

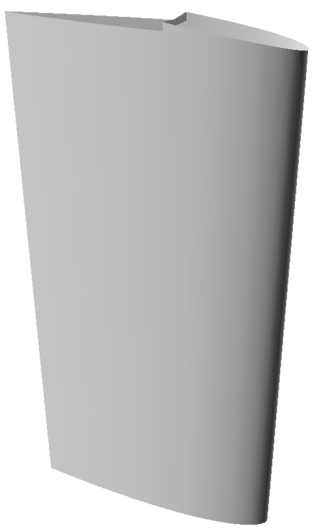

(a) Semi-spade rudder

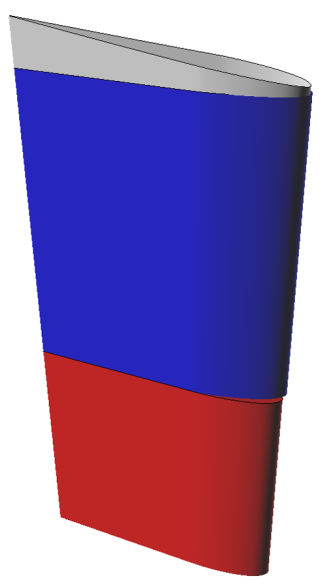

(b) Twisted rudder
Fig. 2 Modeling of semi-spade rudder and twisted rudder

Table 1 Main dimension of semi-spade rudder \& twisted rudder

\begin{tabular}{ccc}
\hline \hline & Semi-spade rudder & Twisted rudder \\
\hline Top chord [mm] & 151.8 & 152.3 \\
Bottom chord [mm] & 126.6 & 120.1 \\
Mean chord [mm] & 139.2 & 136.2 \\
Span [mm] & 250.6 & 248.5 \\
Aspect ratio & 1.8 & 1.82 \\
\hline
\end{tabular}

저자의 실선 비대칭 타 설계 시의 경험을 토대로 표준으로 사 용하는 비틀림 각 $5^{\circ}$ 를 사용하였다.

비대칭 타는 전타(Full-spade rudder)의 일종으로써 혼타의 간 극에서 발생하는 캐비테이션 문제 및 혼(Horn) 뒷부분에 발생하 는 와류를 차단해 주는 장점이 있다. 본 연구에 사용된 혼타 및 비대칭 타의 형상은 Fig. 2와 같으며, 자세한 제원은 Table 1과 같다.

\section{2 러더 벌브 및 프로펠러 캡의 설계}

Fig. 3은 러더 벌브 및 캡의 기호에 관한 정의이다. $W$ 는 러더 벌브의 가로방향 직경, $D$ 는 러더 벌브의 세로방향 직경, $H$ 는 하 류방향의 허브 직경, $\theta$ 는 캡의 각도이다. 러더 벌브와 캡은 프 로펠러 후류의 수축을 억제한다는 관점에서 동일한 목적을 가짐
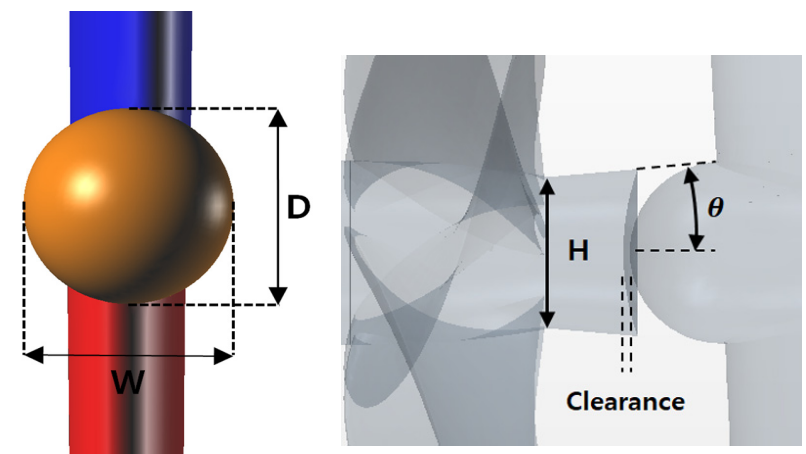

Fig. 3 Definition of rudder bulb size, cap angle, cap bulb clearance and hub diameter 
Table 2 Case study according to design conditions of rudder bulb and cap

\begin{tabular}{|c|c|c|c|c|c|c|c|}
\hline Case & Type & Bulb type & $\begin{array}{c}\text { Clearance } \\
{[\mathrm{mm}]}\end{array}$ & $\begin{array}{c}\theta \\
\text { [degree] }\end{array}$ & $D$ & $W$ & Design conditions \\
\hline \multirow{2}{*}{1} & A & Sphere & 50 & 5 & $1.2 \mathrm{H}$ & $1.2 \mathrm{H}$ & \multirow{2}{*}{ Rudder bulb \& Cap clearance } \\
\hline & $\mathrm{B}$ & Sphere & 70 & 5 & $1.2 \mathrm{H}$ & $1.2 \mathrm{H}$ & \\
\hline \multirow{2}{*}{2} & A & Sphere & 50 & 5 & $1.2 \mathrm{H}$ & $1.2 \mathrm{H}$ & \multirow{2}{*}{ Sphere type \& Parallel type bulb } \\
\hline & $\mathrm{C}$ & Parallel & 50 & 5 & $1.2 \mathrm{H}$ & $1.2 \mathrm{H}$ & \\
\hline \multirow{3}{*}{3} & $\mathrm{D}$ & Sphere & 50 & 2 & $1.1 \mathrm{H}$ & $1.1 \mathrm{H}$ & \multirow{3}{*}{ Cap angle \& Rudder bulb size } \\
\hline & A & Sphere & 50 & 5 & $1.2 \mathrm{H}$ & $1.2 \mathrm{H}$ & \\
\hline & $\mathrm{E}$ & Sphere & 50 & 8 & $1.3 \mathrm{H}$ & $1.3 \mathrm{H}$ & \\
\hline \multirow{2}{*}{4} & $\mathrm{~F}$ & Sphere & 50 & 5 & $1.2 \mathrm{H}$ & $1.3 \mathrm{H}$ & \multirow{2}{*}{ Asymmetric rudder bulb size } \\
\hline & G & Sphere & 50 & 5 & $1.2 \mathrm{H}$ & $1.4 \mathrm{H}$ & \\
\hline
\end{tabular}

으로 하나의 $\mathrm{ESD}$ 처럼 설계하였다. 즉, 캡을 따라 발산된 흐름이 러더 벌브에 유선형으로 이어질 수 있도록 캡의 각도와 벌브의 직경을 하나의 변수로 설계하였다. 러더 벌브의 후류방향 길이 는 비대칭 타의 최대 두께 지점까지 설계하여 비대칭 타의 상 부와 하부 불연속면을 포함하였다. 또한 프로펠러로 인해 수축 되는 후류를 보완해 주기 위해 캡은 발산형으로 $(\theta>0)$, 러더 벌 브의 직경은 허브보다 크게 $(W, D>1 H)$ 설계하였다. 그 후 Table 2 와 같이 4가지 Case를 선정해 캡과 벌브의 성능을 비교하였으 며, 2.2.1 2.2.4절에는 Case에 대한 설계 방법을, 4.2.1 4.2.4절에 는 Case에 대한 전달동력 비교 및 효율 변화 원인을 나타내었 다. Case 1에서는 러더 벌브와 캡의 간극에 따른 성능을 확인해 보았고, Case 2에서는 Mewis and Deichmann(2013)와 Shin et al.(2012)처럼 구형 벌브와 평행한 벌브가 존재하기에 본 연구의 대상선에 적합한 벌브 형상을 확인해 보았다. Case 3에서는 벌 브의 직경을 $1.1 H$ 부터 키워가면서 최적 직경을 찾아보았으며, Case 4에서는 회전하는 후류를 억제하여 곧게 뻗어주도록 벌브 의 가로방향 길이를 키워 성능을 확인해 보았다.

최종적으로 $50 \mathrm{~mm}$ 간극에 $5^{\circ}$ 의 발산각을 가지는 캡, $D=1.2 \mathrm{H}$, $W=1.4 H$ 인 비대칭 구형 벌브에서 Bare hull대비가장 높은 $2.05 \%$ 의 전달동력 감소를 보였다.

2.2.1 러더 벌브와 캡 사이 간극에 따른 설계 (Case 1)

러더 벌브와 캡 사이의 간극을 실선 기준 $50 \mathrm{~mm}$ 와 $70 \mathrm{~mm}$ 로 정하여 자항 성능을 비교하였다(Table 7). 이때 초기 러더 벌브 의 크기는 타 기관과의 러더 벌브 설계 경험을 토대로 $1.2 H$ 로

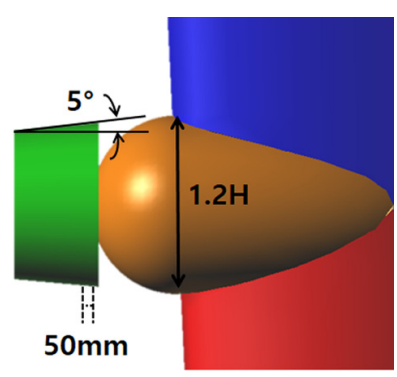

(a) A type

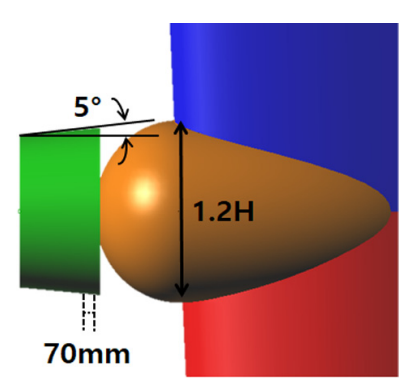

(b) B type
Fig. 4 Modeling of rudder bulb and cap according to rudder bulb \& cap clearance
정하였으며 4.2.3절에서 추가적인 Case study를 통해 러더 벌브 크기를 최적화 하였다.

동일한 조건하에서 비교하기 위해 러더 벌브의 크기 및 캡 각 도는 동일하게 두었으며, 모델링은 Fig. 4 와 같다. 간극에 따른 성 능 비교 결과 $50 \mathrm{~mm}$ 의 간극에서 $70 \mathrm{~mm}$ 보다 약 $0.4 \%$ 우수한 전달 동력 감소를 보였으며, 이를 Case2 4의 고정변수로 두었다. Case study에 따른 자세한 전달동력 비교는 Table 7에 나타내었다.

\subsection{2 러더 벌브의 형상에 따른 설계 (Case 2)}

러더 벌브의 형상을 구형 Type과 발산형 캡과 유선형을 이루 도록 설계한 평행한 Type 2가지로 나누어 전달동력을 비교하였 다. 동일한 비교를 위해 러더 벌브의 크기 및 캡 각도는 일정하 게 두었으며, 모델링은 Fig. 5와 같다. 벌브 형상에 따른 성능 비교 결과 구형 벌브가 평행한 벌브보다 약 $0.8 \%$ 우수한 전달 동력 감소를 보였으며, 이를 Case 3-4의 고정변수로 두었다.

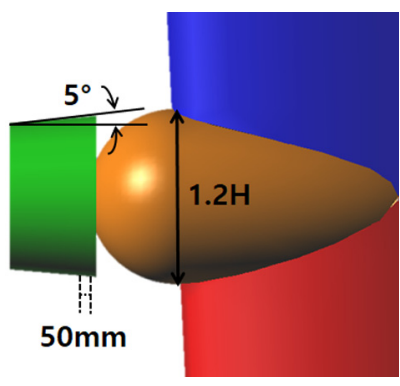

(a) A type

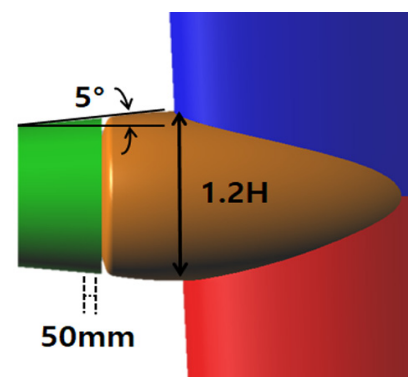

(b) C type
Fig. 5 Modeling of rudder bulb and cap according to rudder bulb type

\subsection{3 러더 벌브 크기와 각도에 따른 설계 (Case 3)}

러더 벌브의 크기 및 캡의 각도는 벌브의 최대 직경과 캡의 연장 선이 만나도록 하나의 변수로 설계하였다. 벌브의 크기는 $1.1 H$ 부 터 키워가며 최적 직경을 찾아보았다. 러더 벌브와 캡 사이 간극은 $50 \mathrm{~mm}$, 벌브 Type은 구형 벌브로 동일하게 설계하였으며, 모델링은 Fig. 6 와 같다. 벌브 크기에 따른 성능 비교 결과, 벌브의 크기가 $1.1 H$ 일 때 보다 $1.2 H$ 일 경우 약 $0.5 \%, 1.3 H$ 일 경우 약 $0.3 \%$ 우수한 전달동력 감소를 보였으며 최적 직경은 $1.2 \mathrm{H}$ 임을 알 수 있었다. 따라서 이를 Case 4 의 고정변수 $(D=1.2 H)$ 로 두었다. 


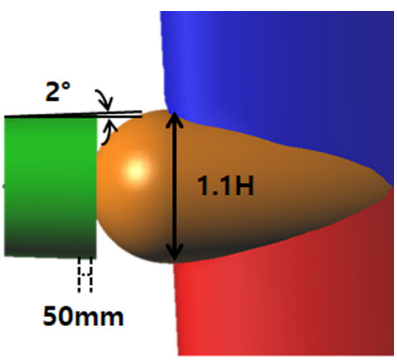

(a) D type

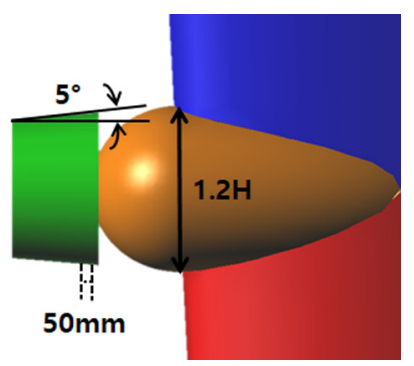

(b) A type

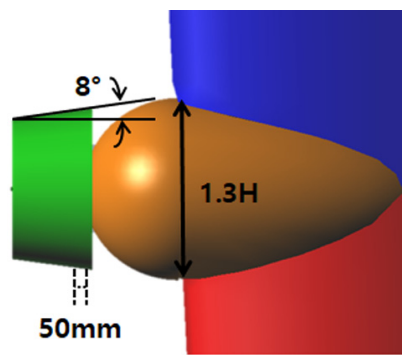

(c) E type

Fig. 6 Modeling of rudder bulb and cap according to cap angle and rudder bulb size

2.2.4 비대칭 러더 벌브 형상에 따른 설계 (Case 4)

비대칭 러더 벌브는 벌브의 가로방향 직경 $(W)$ 이 세로방향 직 경 $(D)$ 에 비해 더 큰 벌브로, 벌브의 가로방향 길이가 프로펠러로 부터 나온 회전하는 흐름을 억제하여 곧게 펴줄 것이라 기대하 여 성능 연구를 해 보았다. 러더 벌브와 캡 사이 간극은 $50 \mathrm{~mm}$, 벌브 Type은 구형 벌브, $D=1.2 H$ 로 동일하게 설계하였다. 또한 이때 캡 각도 $(\theta)$ 는 세로방향 직경 $(D)$ 에 맞추어 정하였으며, 모델 링은 Fig. 7과 같다. 비대칭 벌브 형상에 따른 성능비교 결과, 벌 브의 크기가 $1.2 H / 1.3 H$ 일 때 보다 $1.2 H / 1.4 H$ 일 경우 약 $0.4 \%$ 우 수한 전달동력 감소를 보여 최종적으로 Bare hull대비 약 $2.05 \%$ 의 전달동력 감소를 보였다.

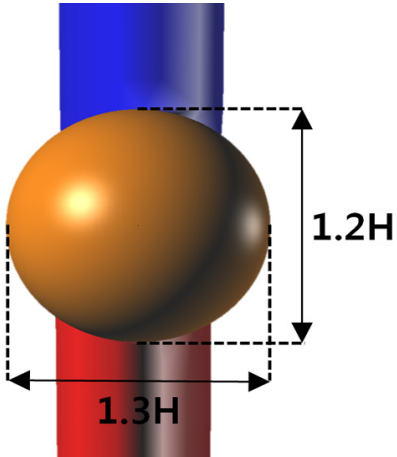

(a) F type

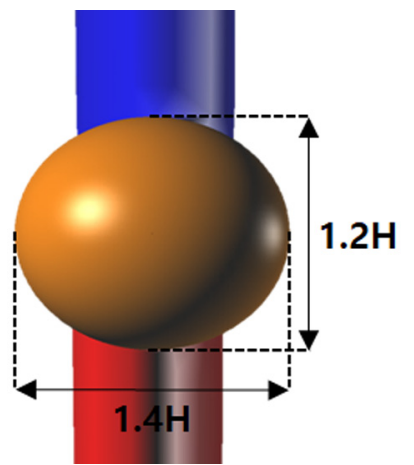

(b) G type
Fig. 7 Modeling of rudder bulb according to asymmetric rudder bulb size

\section{3. 수치해석}

앞서 설계한 Post-device를 STAR-CCM+(v11.02)를 이용하여 자 항성능을 비교하였다. 성능 비교는 자항점에서 알몸선체(Bare hull)
대비 $\mathrm{ESD}$ 부착 시 선박의 전달동력 $\left(2 \pi n_{m} Q_{m}\right)$ 감소로 평가하였다.

\section{1 대상선 제원}

대상선(3,600TEU KRISO container ship)은 부산대학교 예인수 조의 크기에 맞추어 프로펠러의 직경이 $0.2 \mathrm{~m}$ 가 되는 축척비 39.5 로 설계하였으며, 설계속도는 $1.964 \mathrm{~m} / \mathrm{s}$ 이다.

\section{2 지배방정식}

비압축성 난류유동의 지배방정식은 연속방정식(식 (1))과 Reynoldsaveraged Navier-Stokes(RANS) 방정식(식 (2))이며, 다음과 같이 표현 된다.

$$
\begin{aligned}
& \frac{\partial U_{i}}{\partial x_{i}}=0 \\
& \rho \frac{\partial U_{i}}{\partial t}+\rho U_{l} \frac{\partial U_{i}}{\partial x_{l}}=-\frac{\partial p}{\partial x_{i}}+\frac{\partial}{\partial x_{l}}\left(\mu \frac{\partial U_{i}}{\partial x_{l}}-\rho \overline{u_{i} u_{l}}\right)+f_{b i}
\end{aligned}
$$

여기서 $U_{i=(U, V, W)}$ 는 $x_{i}=(x, y, z)$ 방향의 유속이며, $p$ 는 정압, $\rho$ 는 유체밀도, $\mu$ 는 유체점성, $-\rho \overline{u_{i} u_{l}}$ 는 Reynols stress, $f_{b i}$ 는 단위 체적당 물체력을 나타낸다.

\section{3 수치해석 기법}

본 연구의 해석 프로그램은 상용코드인 Star $\mathrm{CCM}+$ Ver. 11.02 를 사용하였고, 난류 모델은 경계층 내에서의 박리유동을 모사 하는데 널리 사용되는 Realizable $k-\varepsilon$ 모델을 채택하였다. 프로 펠러 주위 유동의 모사는 프로펠러와 회전 영역의 격자를 직접 회전시켜주는 Sliding mesh 기법을 사용하였으며, Time step은

Table 3 Comparison of drag, thrust and torque according to time step at $630 \mathrm{rpm}$

\begin{tabular}{cccc}
\hline $\begin{array}{c}\text { Time step } \\
{[\mathrm{s}]}\end{array}$ & $\begin{array}{c}\text { Drag } \\
{[\mathrm{N}]}\end{array}$ & $\begin{array}{c}\text { Thrust } \\
{[\mathrm{N}]}\end{array}$ & $\begin{array}{c}\text { Torque } \\
{[\mathrm{N} \cdot \mathrm{m}]}\end{array}$ \\
\hline 0.001 & 49.04 & 32.76 & 1.11 \\
0.002 & 49.25 & 32.50 & 1.11 \\
\hline Diff. [\%] & 0.43 & -0.78 & -0.39 \\
\hline
\end{tabular}

Table 4 Analysis condition

\begin{tabular}{cc}
\hline \hline Program & STAR-CCM+ (Ver. 11.02) \\
\hline Governing equation & Incompressible RANS \\
Discretization & Cell-centered FVM \\
Turbulence model & Realizable $k-\varepsilon$ model \\
$y^{+}$ & 70 \\
Wall function & Non-equilibrium \\
Velocity-pressure coupling & SIMPLE algorithm \\
Rotation method & Sliding interface moving mesh \\
Cell number & approx. 3,500,000 \\
Time step & $0.002 \mathrm{~s}$ \\
Physical time & $20 \mathrm{~s}$ \\
\hline
\end{tabular}


프로펠러가 한번 회전할 때 약 95회, 48회인 경우로 나누어 성 능을 비교하였다. 결과적으로 저항 및 추력, 토크의 차이가 $1 \%$ 미만으로 보여 계산 시간 대비 좀 더 효율적인 0.002초의 Time step을 사용하였다. Time step에 따른 성능 비교는 Table 3에 나 타내었으며, 자세한 해석조건은 Table 4와 같다.

\section{4 격자계 구성}

본 연구에서는 선체표면에 Trimmer mesh를 주었으며, 좀 더 형상이 복잡한 프로펠러에는 Polyhedral mesh를 사용하여 프로펠 러 주위 유동을 잘 표현할 수 있도록 해주었다. 표면의 초기 격
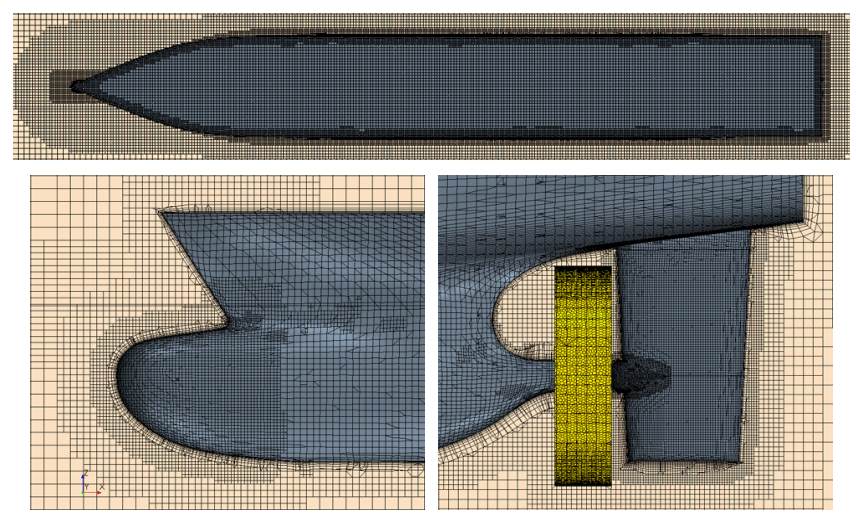

Fig. 8 Numerical grid system for calculations

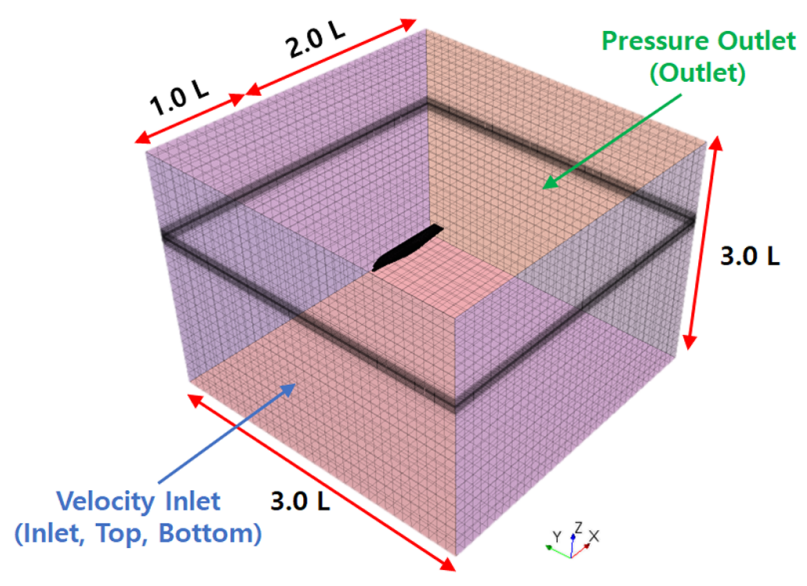

Fig. 9 Computational domain and boundary condition
자 높이를 나타내는 $y^{+}=70$ 으로 두었으며, 선체의 전단력이 잘 표현될 수 있도록 Prism layer(경계층격자)를 6개로 나누어 벽함 수(Wall function)를 적용하였다. 해석을 위한 도메인의 경계조건 은 Inlet, Top, Bottom부분에 Velocity Inlet조건을 주었으며, Outlet 부분에 Pressure Outlet조건을, 그리고 양 Side부분에 Symmetry조 건을 주었다. 위와 같은 격자계를 Fig. 8에 나타냈으며, 경계조건 을 Fig. 9에 나타내었다.

\section{5 수치해석 검증}

$\mathrm{CFD}$ 를 통해 해석한 모델은 난류 모델, 경계층 두께, Time step등 다양한 해석 조건에 따라 결과가 다르다. 따라서 CFD 해석의 결과 값은 검증을 통해 신뢰성을 확보해야한다. 본 연구에서는 선행연 구(Tae, 2017; Kwon, 2013)에서 진행된 KCS선박의 Model test를 통해 $\mathrm{CFD}$ 의 저항 및 공칭반류를 비교하였다(Table 5, Fig. 10).

Table 5 Comparison of resistance coefficient at model scale

\begin{tabular}{cc}
\hline \hline Resistance coefficient & $C_{T M} \times 10^{3}$ \\
\hline CFD & 3.951 \\
Model test & 3.938 \\
Difference (\%) & 0.318 \\
\hline
\end{tabular}

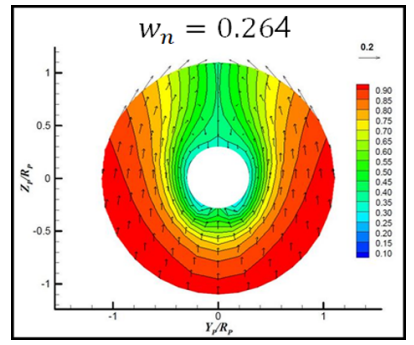

(a) CFD

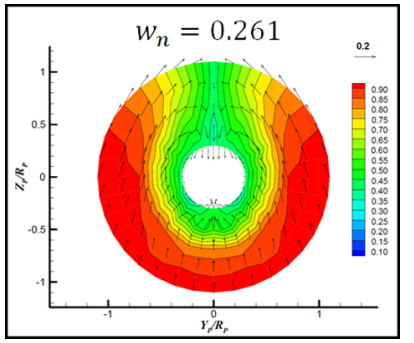

(b) Model test
Fig. 10 Comparison of nominal wake at propeller plane

\section{4. 수치해석 결과}

\section{1 저항성능 결과}

자항상태와 동일한 해석 조건을 사용하여 격자계의 일관성을 유지하였으며, 러더 벌브 및 캡을 포함한 저항 값을 확인하기

Table 6 Comparison of resistance according to case study

\begin{tabular}{cccccc}
\hline \hline Case & Type & Division & $C_{T S} \times 10^{3}$ & EHP [PS] & EHP_Diff. [\%] \\
\hline \multicolumn{2}{c}{ Bare hull } & - & 2.498 & 31643 & 0.00 \\
\hline \multirow{2}{*}{1} & A & $50 \mathrm{~mm}$ clearance & 2.497 & 31641 & -0.01 \\
& $\mathrm{~B}$ & $70 \mathrm{~mm}$ clearance & 2.511 & 31817 & 0.55 \\
\hline \multirow{2}{*}{2} & $\mathrm{~A}$ & Sphere type bulb & 2.497 & 31641 & -0.01 \\
& $\mathrm{C}$ & Parallel type bulb & 2.507 & 31774 & 0.41 \\
\hline \multirow{2}{*}{3} & $\mathrm{D}$ & $2^{\circ} / 1.1 \mathrm{H} / 1.1 \mathrm{H}$ & 2.515 & 31859 & 0.68 \\
& $\mathrm{~A}$ & $5^{\circ} / 1.2 \mathrm{H} / 1.2 \mathrm{H}$ & 2.497 & 31641 & -0.01 \\
& $\mathrm{E}$ & $8^{\circ} / 1.3 \mathrm{H} / 1.3 \mathrm{H}$ & 2.515 & 31870 & 0.72 \\
\hline \multirow{2}{*}{4} & $\mathrm{~F}$ & $5^{\circ} / 1.2 \mathrm{H} / 1.3 \mathrm{H}$ & 2.509 & 31796 & 0.48 \\
\end{tabular}


위해 프로펠러 블레이드를 제거한 Dummy hub를 사용하였다. Case에 따른 자세한 저항성능 결과는 Table 6과 같다.

설계 속도인 24 노트 $(44.448 \mathrm{~km} / \mathrm{h})$ 에서 결과를 비교하였으며, 각 Case별로 저항 값의 차이는 $1 \%$ 미만의 작은 차이를 보였지만, 특이한 점은 러더 벌브의 크기가 커질수록 저항이 커지는 것이 아닌 일정한 크기에서 저항이 가장 작아지는 최적 크기가 존재 한다는 것이었다. 이를 통해 러더 벌브의 연구는 본 연구와 같은 Case study를 통해 최적 직경을 도출해야 한다고 판단하였다.

\section{2 자항성능 결과}

자항점(Self-propulsion point)에서의 모형의 전 저항 $R_{T M}^{S P}$, 추력 $T_{M}$, 토크 $Q_{M}$, 회전수 $n_{M}$ 를 구하기 위하여 두 개의 프로펠러 회 전수에 대한 해석 결과를 내삽(Interpolation)하여 구하였다. 해석 방법으로는 ITTC(International towing tank conference) 1978 Method를 기반으로 한 2차원 방법 $(1+k=1)$ 으로 실선 성능을 추 정하였다. Table 7에서는 설계 속도인 24 노트 $(44.448 \mathrm{~km} / \mathrm{h})$ 에서 Case에 따른 자항 요소 및 전달동력 비교를 나타내었으며, 4.2.1 4.2.4절에서는 러더 벌브 주변 유선비교(Figs. 11-14)를 통해 효율 증가 원인을 나타내었다.

4.2.1 러더 벌브와 캡 사이 간극에 따른 수치해석 결과 (Case 1) 러더 벌브와 캡 사이 간극이 $50 \mathrm{~mm}$ 일 때 내부에서 발생하는 와 류가 감소하여 저항이 감소하는 것을 Table 6의 EHP(Effective

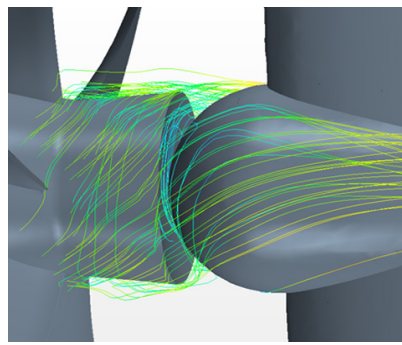

(a) A type

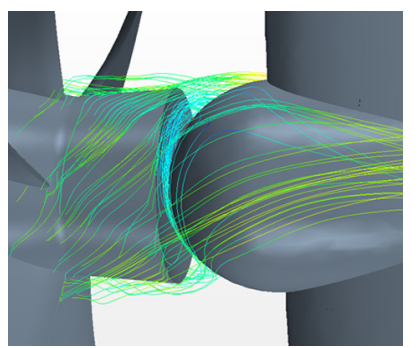

(b) B type
Fig. 11 Comparison of streamline accordingy to rudder bulb \& cap clearance horse power)와 Fig. 11을 통해 확인하였고, 이로 인해 간극에 따 른 준추진효율의 차이는 크지 않지만 DHP(Delivered horse power) 의 정량적인 값이 감소하는 것을 확인하였다(Table 7).

4.2.2 러더 벌브의 형상에 따른 수치해석 결과 (Case 2)

러더 벌브의 형상이 평행한 형상일 때 프로펠러에서 나온 회 전하는 흐름이 벌브의 방해를 받지 않고 그대로 흘러 벌브를 지난 후 아래 방향으로 나아가는 것을 볼 수 있지만, 구형 벌브 의 경우 벌브의 형상에 의해 흐름의 회전이 제한되면서 벌브를 지난 후 곧게 뻗어나가는 것을 확인하였다(Fig. 12).

이를 자항요소를 통해 비교하면, 흐름이 구형 벌브에 제한되 어 반류가 증가하지만 그와 동시에 추력감소계수도 증가하여 두 벌브의 선각효율은 큰 차이를 보이지 않는다. 허나 구형 벌 브를 통해 회전에너지를 회수함으로써 동일한 추력을 내는데 요구되는 회전수 및 토크가 줄어들게 되고 추력일치법을 사용 하였을 때 상대회전효율이 더 높아지는 것을 확인하였다. 그에 따라 준추진효율이 증가하게 되고 $\mathrm{DHP}$ 가 감소하는 것을 확인 하였다(Table 7).

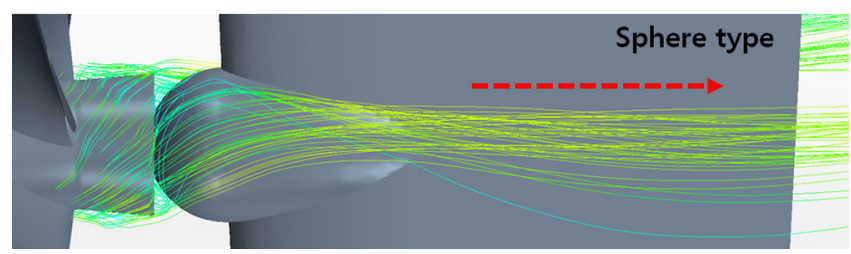

(a) A type

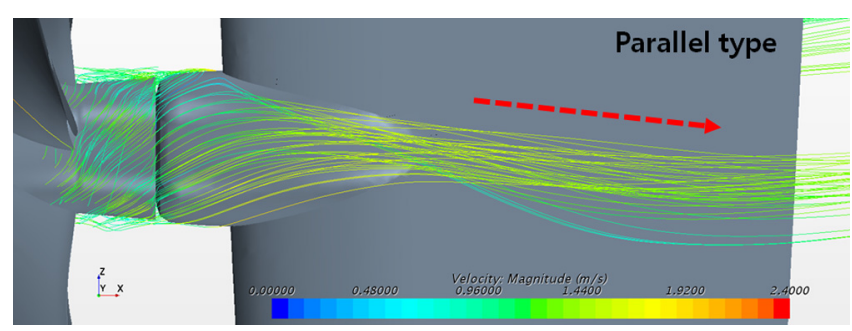

(b) C type

Fig. 12 Comparison of streamline according to rudder bulb type

Table 7 Comparison of self-propulsion performance according to case study

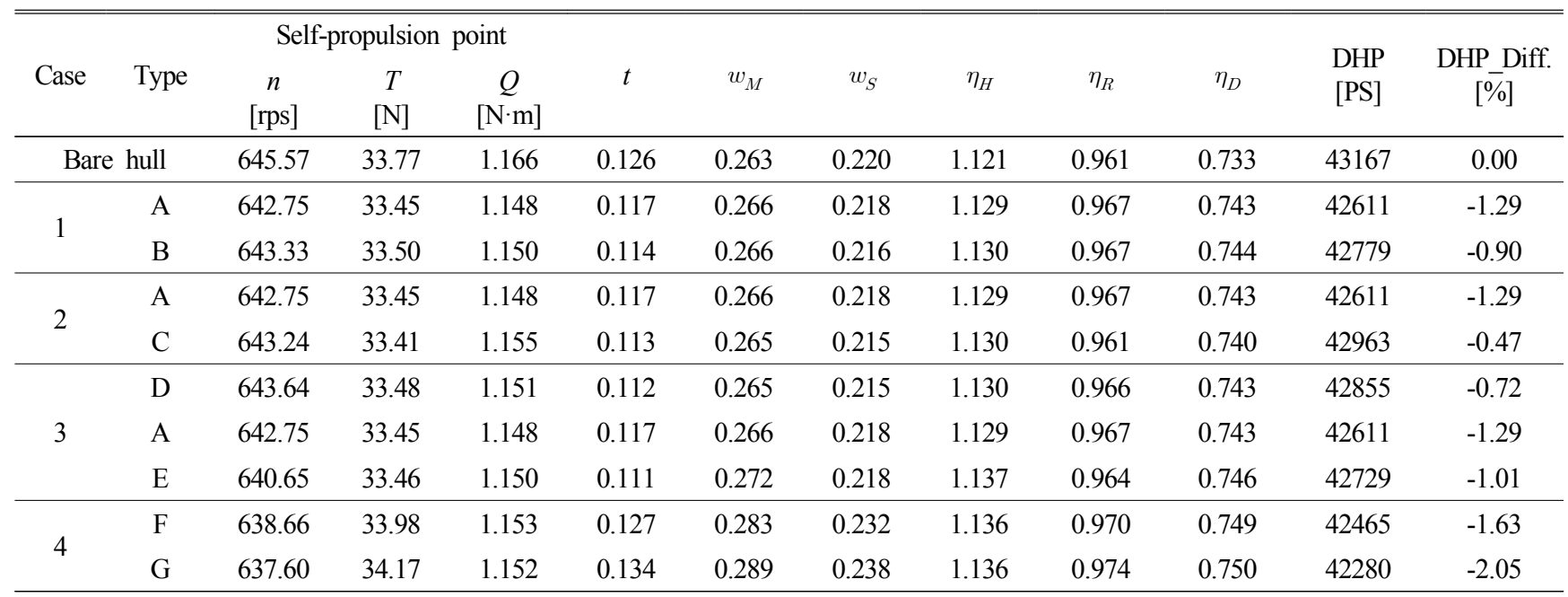


4.2.3 러더 벌브 크기와 각도에 따른 수치해석 결과 (Case 3)

Fig. 13을 통해 러더 벌브 표면을 타고 흐르는 유선(점선 화살 표)을 비교해 보았을 때 D type 및 E type은 프로펠러에서 나온 회전된 흐름이 벌브 상부에서 휘어져 벌브를 지난 후 오히려 아래 방향으로 나아가는 것을 확인할 수 있다. 허나 A type의 경우 회전된 흐름이 벌브에 의해 적절히 억제되어 벌브를 지난 후 곧게 뻗어나가는 것을 확인할 수 있다. 이러한 원인으로 Table 6과 같이 A type의 EHP가 가장 적은 것으로 사료된다. Table 7의 자항요소를 비교해 보면, 러더 벌브의 크기가 커질수 록 반류비가 커지며 그에 따라 벌브의 크기가 가장 큰 E type에 서 선각효율 및 준추진 효율이 가장 큰 것을 확인할 수 있다. 그러나 A type의 벌브가 가장 적은 $\mathrm{EHP}$ 값을 가지기 때문에 $\mathrm{DHP}$ 또한 $\mathrm{E}$ type보다 적은 값을 갖게 되어 Bare hull대비 가장 우수한 DHP감소를 보였다.

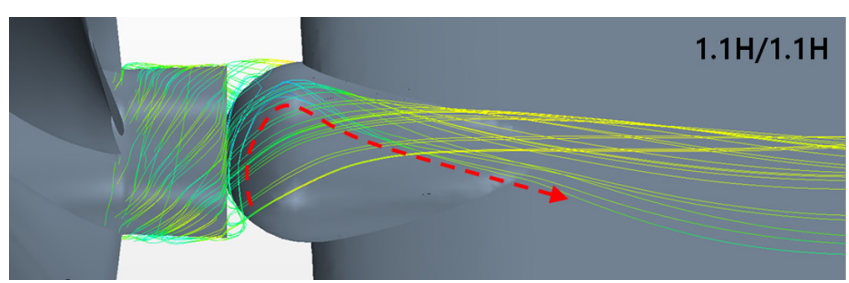

(a) D type

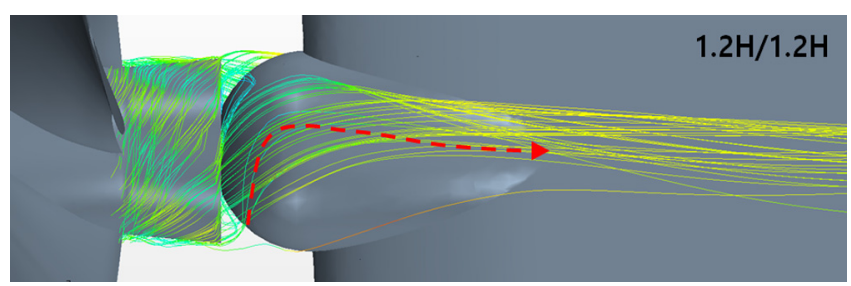

(b) A type

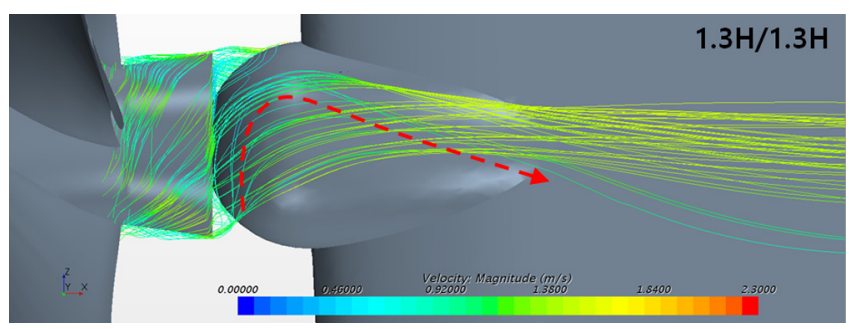

(c) E type

Fig. 13 Comparison of streamline according to rudder bulb type size

4.2.4 비대칭 러더 벌브의 형상에 따른 수치해석 결과 (Case 4) Fig. 14를 통해 러더 벌브 표면을 타고 흐르는 유선을 비교해 보았을 때 D type 및 E type의 벌브보다 흐름이 과도하게 휘어 지지 않고 벌브 전체에 걸쳐 고르게 분포되어 있는 것을 확인 할 수 있다. 이러한 원인으로 Table 6와 같이 F type 및 G type 의 $\mathrm{EHP}$ 가 벌브 크기에 비해 비교적 적은 값을 가지는 것으로 사료된다. Table 7의 자항요소를 비교해 보면, 벌브의 가로방향 길이가 길어지지만 캡의 각도는 $5^{\circ}$ 로 고정해 두었기 때문에 오 히려 E type보다 큰 반류비를 가진다. 그에 따라 선각효율 및

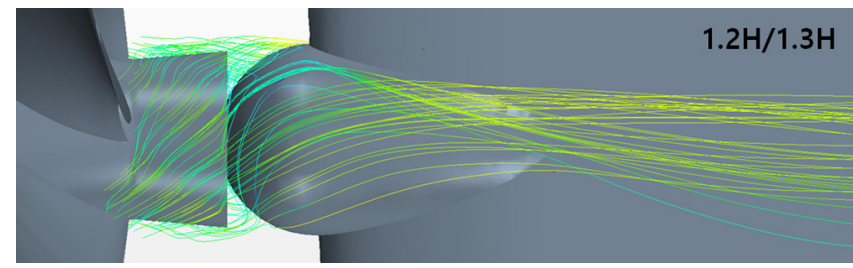

(a) F type

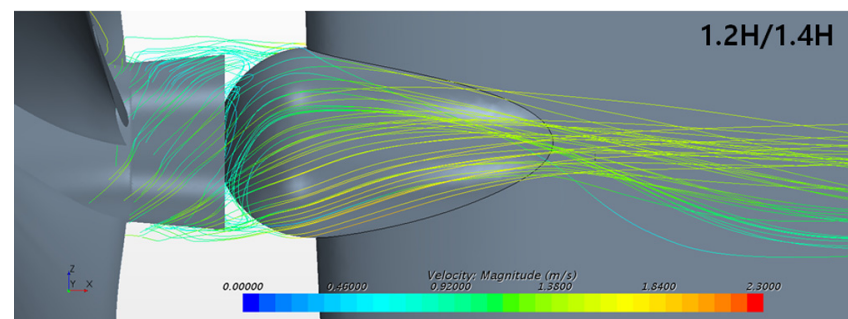

(b) G type

Fig. 14 Comparison of streamline according to asymmetric rudder bulb type

준추진 효율이 증가하며 최종적으로 $\mathrm{G}$ type $\mathrm{ESD}$ 에서 Bare hull $\mathrm{DHP}$ 대비 $2.05 \%$ 감소를 보여 저항 및 자항 측면에서 가장 최적 화된 $\mathrm{ESD}$ 를 설계할 수 있었다.

\section{5. 결 론}

본 논문에서는 $\mathrm{KCS}$ 에 최적화된 Post-device를 설계하여 설계 속도인 24 노트 $(44.448 \mathrm{~km} / \mathrm{h})$ 에서 $\mathrm{CFD}$ 를 통해 저항 및 자항성능 을 비교하였다. Post-device의 최적화를 위해 러더 벌브 및 프로 펠러 캡을 설계변수로 두고 4가지 Case study를 통해 성능을 비 교하였다. Case 1에서는 러더 벌브와 캡의 간극에 따른 성능을 확인해 보았고, Case 2에서는 본 연구의 대상선에 적합한 벌브 형상을 확인해 보았다. Case 3 에서는 벌브의 직경을 $1.1 H$ 부터 키워가면서 최적 직경을 찾아보았으며, Case 4에서는 회전하는 후류를 억제하여 곧게 뻗어주도록 벌브의 가로방향 길이를 키 워 주었다. 이로부터 다음과 같은 결론을 얻을 수 있었다.

(1) 러더 벌브 및 캡 사이 간극이 실선 기준 $50 \mathrm{~mm}$ 일 경우, $70 \mathrm{~mm}$ 일 때보다 내부에 발생하는 와류가 감소하여 저항이 감소 하고 그로 인해 DHP 저감 측면에서 약 $0.4 \%$ 의 우수한 성능을 가진다.

(2) 러더 벌브의 형상이 구형일 때, 평행한 형상보다 후류의 회전을 억제하여 곧게 펴줄 수 있어 $\mathrm{DHP}$ 저감 측면에서 약 $0.8 \%$ 의 우수한 성능을 가진다.

(3) $\mathrm{KCS}$ 선박의 경우 러더 벌브의 크기가 $1.2 H$ 일 때, $1.1 H$, $1.3 H$ 인 경우보다 후류의 회전을 곧게 펴줄 수 있어 저항 측면에 서도 유리하며 $\mathrm{DHP}$ 저감 측면에서도 각각 약 $0.5 \%, 0.3 \%$ 의 우 수한 성능을 가진다. 따라서 러더 벌브의 연구 시 최대 효율을 내는 최적 직경은 본 연구와 같은 Case study를 통해 도출해야 한다.

(4) 러더 벌브의 가로방향 직경이 세로방향에 비해 큰 형상은 벌브 표면을 따라 흐르는 유선이 벌브 전체에 걸쳐 고르게 분 포되어 저항 측면에서도 유리하며 벌브의 가로방향 크기에 의 
해 반류비가 커져 선각효율 및 준추진효율이 증가한다. 최종적 으로 $50 \mathrm{~mm}$ 간극에 $5^{\circ}$ 의 발산각을 가지는 캡, 가로 $1.4 H$, 세로 $1.2 H$ 인 비대칭 구형 벌브에서 Bare hull대비 가장 높은 $2.05 \%$ 의 $\mathrm{DHP}$ 감소를 보였으며, 선행연구인 Tae(2017)의 Twisted rudder 대비 $0.73 \% \mathrm{DHP}$ 감소를 보였다.

\section{후 기}

이 논문은 부산대학교 기본연구지원사업(2년)에 의하여 연구 되었음.

\section{References}

Carlton, J., 1994. Marine Propellers and Propulsion. $1^{\text {st }}$ Edition, Butterworth-Heinemann, Great Britain.

Cha, K.J., 2017. Design of Twisted Rudder with Bulb and Fin for KCS. Master's Thesis, Naval Architecture and Ocean Engineering in Pusan National University.

Heo, D.H., 2017. Resistance and Propulsion Performance Comparison of Semi Spade Rudder and Asymmetric Full Spade Rudder by Numerical and Experimental Method. Master's Thesis, Naval Architecture and Ocean Engineering in Pusan National University.

Kim, I.W., Kim, M.C., Lee, J.H., Chun, J.H., Jung, U.H., 2009. Study on Design of a Twisted Full-Spade Rudder for a Large Container Ship by the Genetic Algorithm. Journal of the Society of Naval Architects of Korea, 43(5), 479-487.

Kim, J.H., Choi, J.E., Choi, B.J., Chung, S.H., 2014. Twisted Rudder for Reducing Fuel-oil Consumption. International Journal of Naval Architecture and Ocean Engineering, 6(3), 715-722.

Kwon, J.I., 2013. A Study on the Biased Asymmetric Pre-swirl Stator For a Container Ship. Master's Thesis, Naval Architecture and Ocean Engineering in Pusan National University.

Mewis, F., Deichmann, F., 2013. Power-and Cost-Savings for Container Vessels by Hydrodynamic Energy Saving Devices. Proceedings of the $4^{\text {th }}$ International Ship Efficiency Conference, Hamburg Germany.

Nielsen, J.R., Shin, K.W., Lundgren, E., Faghani, F., 2012. Combined Kappel Propeller and Rudder Bulb System For Improved Propulsion Efficiency. Proceedings of the $34^{\text {th }}$ Motorship Propulsion \& Future Fuels Conference, Hamburg Germany.

Okada, Y., Kawasaki, M., Katayama, K., Okazaki, A., Fukuda, K., Okazaki, M., 2015. The development of "Ultimate Rudder" for EEDI. Proceedings of International Conference on Computational Methods in Marine Engineering, Rome Italy.

Shin, K.W., Lundgren, E., Nielsen, J.R., 2012. CFD-Based Optimization of Rudder Bulb Systems. Proceedings of World Maritime Technology Conference, Saint-Petersburg, Russia.

Tae, H.J., 2017. A Numerical and Experimental Performance Study on Rudder with Wavy Configuration at High Angles of Attack. Master's Thesis, Naval Architecture and Ocean Engineering in Pusan National University. 